\title{
Development and Validation of a New Comprehensive Method for Heavy Metal Pollution Assessment in Soil Media
}

\section{Bello $\mathrm{S}^{1 *}$, Muhammad BG ${ }^{1}$, Simon $\mathrm{J}^{2}$ and Bature $\mathrm{B}^{3}$}

${ }^{1}$ Department of Physics, Umaru Musa Yar'adua University Katsina, Nigeria

${ }^{2}$ Department of Physics, Ahmadu Bello University Zaria, Nigeria

${ }^{3}$ Department of Mathematics, Umaru Musa Yar'adua University Katsina, Nigeria

\begin{abstract}
This study was carried out to develop and validate a new comprehensive methodology for the assessment of heavy metal pollution in soil environmental media. The models were developed to fill up the gap between the existing contamination factor indices and hazard quotient, so as to avoid discrepancies in their application. The results obtained from analysis of heavy metals $(\mathrm{Zn}, \mathrm{Cu}, \mathrm{Ni}$ and $\mathrm{Cd}$ ) in soil samples collected from Dana steel limited dumpsite upper layer were used for the validation. The existing hazard quotient and contamination factors classify $\mathrm{Cu}$ under very high pollution category. The existing Pollution load and the developed hazard load index characterized the dumpsite under considerably polluted category. Discrepancy was observed in the single index classification against $\mathrm{Zn}, \mathrm{Ni}$ and $\mathrm{Cd}$. This discrepancy was attributed to the possible improper control area selection. The proposed methodology if utilized is capable of relieving the need for control area sampling there by eliminating biasness in the environmental quality deterioration assessment.
\end{abstract}

Keywords: Heavy metals; Hazard quotient; Contamination factors; Pollution load index; Hazard load index

\section{Introduction}

According to a continuous monitoring data collected in 118 cities in china between 2-7 years, only $3 \%$ of the urban ground water meets the basic standards of cleanliness, $64 \%$ is suffering very heavy metal pollution and about $33 \%$ is suffering moderate pollution [1]. Heavy metals pollution assessment nowadays is becoming an important task due to the increase in man-made sources of heavy metals in terms of petrochemicals, compost, pesticides, animal manures, sewage sludge, leaded paints as well as the indiscriminate dumping of wastes in landfills [2]. These heavy metals when taken up in to the body even at trace amounts are capable of accumulating gradually until they reach the toxicity limit provided that their rate of entry is higher than that of their excretion [3]. Heavy metals accumulation has shown to be detrimental to both plants and animals.in human body, for example, it is capable of causing neurological disorders, damage to the internal organs of the body and even death while in plants it shows negative effects on photosynthesis and absorption/exchange of gases [4-7].

Heavy metals risk assessment has been carried out in different media using various methods. The heavy metal contamination due to fish intake has been assessed using daily intake of metal (DIM) and health risk indices by considering the daily loading of metals into the body which depend body weight of the consumer and the relative bioavailability of the metals being studied as cited by Hassaan [8], El-Rayis et al. [9] and USEPA [10]. Heavy metals contamination assessment in drinking water has been carried out successfully all over the world using quality index method. These quality index method has proved to be a significant tool for effectively gathering a composite influence of indicators to the overall contamination [11]. Several evaluation methods have been utilized by various authors in heavy metal pollution assessment in soils and sediments: Single index factor $(\mathrm{Pi})$, Nemerow's pollution index $(\mathrm{PN})$, potential ecological risk index (RI), enrichment factor (EF), contamination factor (CF), geoaccumulation index (Igeo), contamination index (Cd), pollution load index (PLI) as well as hazard quotient [12-20]. Pi and CF are computed as basis for obtaining PN and PLI respectively. Igeo can be used to distinguish the effects that human activities have on the environment [21]. RI considers the toxicity of the pollutant as a means of evaluating the ecological risk, the value does so by comparing the concentration of the pollutant with the background value. EF represents the value that assess anthropogenic influences on heavy metals in sediments, the measurement uses aluminum (Al) as a conservative element [13]. However, discrepancies are usually observed in the application of these methods due to their varying assumptions. This Study therefore proposes to develop models/classification that could be used to assess the heavy metal contamination severity in hazard quotient in a way to fill the gap between it and the existing contamination factor models. The proposed methodology was validated using the data on heavy metal pollution by $\mathrm{Zn}, \mathrm{Cu}, \mathrm{Ni}$ and $\mathrm{Cd}$ in top soils of Dana steel limited dumpsite.

\section{Materials and Methods}

Study area used in the validation/sample preparation and analysis

Top soils of Dana steel limited dumpsite located in Katsina state Nigeria was used in the validation of the developed condition and models. The site was the same as that reported in my previous studies. Similarly, all the collected soil Samples were prepared and analyzed using the standard flame atomic absorption spectrophotometry method as utilized in the other studies [22-25].

Existing statistical indices in use for environmental quality assessment

Contamination factor (CF): Contamination factor (CF) is also

*Corresponding author: Bello S, Department of Physics, Umaru Musa Yar'adua University Katsina, Katsina state, Nigeria, Tel: +2348166791940; E-mail: suleiman.bello@umyu.edu.ng

Received May 30, 2017; Accepted June 20, 2017; Published June 27, 2017

Citation: Bello S, Muhammad BG, Simon J, Bature B (2017) Development and Validation of a New Comprehensive Method for Heavy Metal Pollution Assessment in Soil Media. Int J Swarm Intel Evol Comput 6: 160. doi: 10.4172/20904908.1000160

Copyright: $\odot 2017$ Bello S, et al. This is an open-access article distributed unde the terms of the Creative Commons Attribution License, which permits unrestricted use, distribution, and reproduction in any medium, provided the original author and source are credited. 
called single pollution index (PI). Contamination factor is the quotient obtained by dividing the concentration of metals related to the target area by reference area. Their results are mostly associated with single pollution load, while their n-root was used for integrated pollution load index. The contamination factor can be calculated through the following formula as suggested by Kumar et al. [24].

$$
C F=C n / B n
$$

In the above equation, $\mathrm{Cn}$ is the concentration of metals in the target area and $\mathrm{Bn}$ is the metals concentration of the reference area. $\mathrm{CF}$ is categorized as tabulated in Table 1.

Pollution load index: Pollution load index (PLI) is simple statistical technique used to provide comprehensive information about the metals toxicity in respective samples [26,27]. Pollution load index is usually calculated through the following formula:

$$
P L I=\sqrt[n]{C F_{1} * C F_{2} * C F_{3} * \ldots \ldots \ldots . C F_{n}}
$$

Where, PLI represents the pollution load index, CF is the contamination factor and $\mathrm{n}$ is the number of elements. If $\mathrm{PLI}<1$ it indicates that there is low pollution. while PLI $>1$ indicates the presence of pollution.

Hazard quotient: The soil Hazard Quotient (HQ) is the ratio of the heavy metal concentration of surveyed soil samples to reference permissible limit and is computed using the relation,

$$
\mathrm{HQ}=\mathrm{Cc} / \mathrm{Cp}
$$

Where, $\mathrm{Cp}$ and $\mathrm{Cc}=$ reference maximum permissible limit of heavy metal concentration and the concentration obtained in the sampled area, respectively.

\section{Results and Discussion}

\section{The proposed new method}

The models and classifications: The models and classifications proposed were directly analogous to the contamination factor indices and pollution load index, only that the developed models utilize Hazard quotients as the input parameters in lieu of contamination factors [28]. The developed analogous formula was termed Hazard load index to distinguish it from the popularly known pollution load index. The proposed hazard load index if used will provide comprehensive information on the pollution severity in a typical heavy metals pollution assessment. The classification as adopted and amended was presented in Table 2 .

The proposed hazard load index: Similar to the pollution load index that takes contamination factors as inputs, an analogous relation

\begin{tabular}{|c|c|}
\hline Contamination factor & Classification \\
\hline $\mathrm{CF}<1$ & Low contamination \\
\hline $1 \leq \mathrm{CF}<3$ & Moderate contamination \\
\hline $3 \leq \mathrm{CF}<6$ & Considerable contamination \\
\hline $\mathrm{CF} \geq 6$ & Very high contamination \\
\hline
\end{tabular}

Table 1: Classification of contamination factors.

\begin{tabular}{|c|c|}
\hline Hazard quotient & Classification \\
\hline $\mathrm{HQ}<1$ & Low \\
\hline $1 \leq \mathrm{HQ}<3$ & Moderate \\
\hline $3 \leq \mathrm{HQ}<6$ & Considerable \\
\hline $\mathrm{HQ} \geq 6$ & Very high \\
\hline
\end{tabular}

Table 2: Classification of hazard quotient. termed hazard load index was developed by adoption and amendment of the pollution load equation and was presented in equation 4 .

$$
H L I=\sqrt[n]{H Q_{1}{ }^{*} H Q_{2} * H Q_{3} * \ldots \ldots \ldots . . H Q_{n}}
$$

The existing pollution load and hazard indices do not provide information on the severity or extent of the contamination or pollution of an environment by heavy metals. These information is very important for planning an appropriate legislation and/or remediation measure, as such, this work propose the classification provided in Table 3 .

\section{Validation of the developed method}

Contamination factors (Existing method): The contamination factors corresponding to each heavy metal in a particular soil sample was calculated and the results were presented in the Table 4 . From the mean contamination factors of each heavy metal and based on the classification described we could observe that $\mathrm{Zn}$ and $\mathrm{Cu}$ are in very high pollution category, $\mathrm{Ni}$ falls under considerable pollution category while $\mathrm{Cd}$ can be considered in moderate pollution category (Table 4).

The modified hazard quotients classification: The hazard quotients corresponding to each heavy metal in a particular soil sample was calculated and the results were presented in the Table 5. From the mean hazard quotient of each heavy metal and based on the

\begin{tabular}{|c|c|}
\hline PLI or $\mathrm{HLI}$ & Classification \\
\hline $\mathrm{PLI}$ or $\mathrm{HLI}<1$ & Low \\
\hline $1 \leq \mathrm{PLI}$ or $\mathrm{HLI}<3$ & Moderate \\
\hline $3 \leq \mathrm{PLI}$ or $\mathrm{HLI}<6$ & Considerable \\
\hline $\mathrm{PLI}$ or $\mathrm{HLI} \geq 6$ & Very high \\
\hline
\end{tabular}

Table 3: Classification pollution load and hazard load indices.

\begin{tabular}{|c|c|c|c|c|}
\hline $\begin{array}{c}\text { Sample } \\
\text { No. }\end{array}$ & CF (Zn) & CF (Cu) & CF (Ni) & CF (Cd) \\
\hline 1 & 12.77181 & 79.15789 & 4.825175 & 0.153846 \\
\hline 2 & 18.10403 & 42.26316 & 3.594406 & 0.815385 \\
\hline 3 & 12.63758 & 9.026316 & 1.391608 & 0.969231 \\
\hline 4 & 19.6443 & 72.34211 & 8.111888 & 2.353846 \\
\hline 5 & 15.0302 & 18.42105 & 2.524476 & 1.446154 \\
\hline 6 & 9.647651 & 23.65789 & 2.867133 & 1.492308 \\
\hline 7 & 4.671141 & 2.315789 & 0.559441 & 0.984615 \\
\hline 8 & 10.53356 & 3.473684 & 8.27972 & 1.707692 \\
\hline 9 & 12.38926 & 3.973684 & 1.363636 & 1.307692 \\
\hline Mean & $\mathbf{1 2 . 8 2 6}$ & $\mathbf{2 8 . 2 9 2}$ & $\mathbf{3 . 7 2 4}$ & $\mathbf{1 . 2 4 8}$ \\
(Range) & $\mathbf{( 4 . 6 7 1 - 1 9 . 6 4 4 )}$ & $\mathbf{( 2 . 3 1 6 - 7 9 . 1 5 8 )}$ & $\mathbf{( 0 . 5 5 9 - 8 . 2 8 0 )}$ & $\mathbf{( 0 . 1 5 4 - 2 . 3 5 4 )}$ \\
\hline
\end{tabular}

Table 4: Calculated contamination factors corresponding to each heavy metal concentration in the studied samples.

\begin{tabular}{|c|c|c|c|c|}
\hline Sample No. & $\mathbf{H Q}(\mathbf{Z n})$ & $\mathbf{H Q}(\mathbf{C u})$ & $\mathbf{H Q} \mathbf{( N i )}$ & $\mathbf{H Q}(\mathbf{C d})$ \\
\hline 1 & 3.806 & 20.05333 & 1.725 & 0.666667 \\
\hline 2 & 5.395 & 10.70667 & 1.285 & 3.533333 \\
\hline 3 & 3.766 & 2.286667 & 0.4975 & 4.2 \\
\hline 4 & 5.854 & 18.32667 & 2.9 & 10.2 \\
\hline 5 & 4.479 & 4.666667 & 0.9025 & 6.266667 \\
\hline 6 & 2.875 & 5.993333 & 1.025 & 6.466667 \\
\hline 7 & 1.392 & 0.586667 & 0.2 & 4.266667 \\
\hline 8 & 3.139 & 0.88 & 2.96 & 7.4 \\
\hline 9 & 3.692 & 1.006667 & 0.4875 & 5.666667 \\
\hline Mean & $\mathbf{3 . 8 2 2}$ & $\mathbf{7 . 1 6 7}$ & $\mathbf{1 . 3 3 1}$ & $\mathbf{5 . 4 0 7}$ \\
(Range) & $\mathbf{( 1 . 3 9 2 - 5 . 8 5 4 )}$ & $\mathbf{( 0 . 5 8 7 - 2 0 . 0 5 3 )}$ & $\mathbf{( 0 . 2 - 2 . 9 6 )}$ & $\mathbf{( 0 . 6 6 7 - 1 0 . 2 )}$ \\
\hline
\end{tabular}

Table 5: Calculated hazard quotients corresponding to each heavy metal concentration in the studied samples. 


\section{PLI VS HLI}

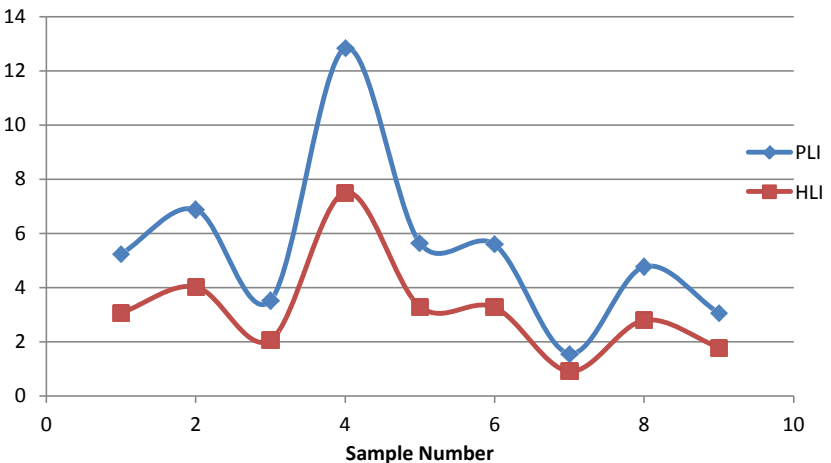

Figure 1: A scatter plot showing the pollution load index values of each grid sample relative to hazard load index.

classification developed in this work, we could observe that $\mathrm{Zn}$ and $\mathrm{Cd}$ are in considerable pollution category, $\mathrm{Cu}$ in very high pollution category and Ni falls under moderate pollution category which to a reliably higher extent agree with the existing classification in 3.2.2 (Table 5).

\section{The pollution load index (existing) vs. the proposed hazard load index (new method)}

Pollution load index was the popular index used in assessing the environmental quality deterioration due to all studied heavy metals. This index was calculated and the results were presented in a scatter plot Figure 1. The developed hazard load index was similarly used in the same study, each based on its assumptions and inputs, and the obtained calculated results were plotted in the same plot for comparison sake. Both the mean pollution load index and the mean hazard load index classified the studied site under considerably polluted category [29]. Meanwhile, observing the individual data points in the plot we could deduce that pollution load index overestimated the hazard possibly due to the improper guide on control area sampling which was evidently required in hazard assessment via pollution load index (Figure 1).

\section{Conclusion}

In this paper a new comprehensive methodology for heavy metals pollution assessment has been proposed and validated. The new method developed provides a hazard quotient grading/classification of the pollution severity in a typical soil heavy metals pollution assessment. The proposed classification if used is capable of relieving researchers of the need for control area sampling as it uses the threshold values set by a reliable legislation/organization thereby minimizing cost, time as well as errors that may be inherently encountered. In this methodology, all that is needed is to sample the soil to be studied for pollution, take it to the analytical laboratory for analysis of the heavy metals concentrations, obtain the current threshold limit of the heavy metals under study and apply the proposed equation with its classification system to obtain the status and severity of its pollution. This assessment method, however, may have some deficiencies and may require verification through more research in order to seek for the possibility of its application to cases other than soil pollution sites. The proposed evaluation method is more objective and reasonable compared to the contamination index method as even the site selected as a control in the existing contamination index classification may be polluted and may be subject to biasness. This research therefore provides an important frame of reference to the government decision-making on environment improvement/impact assessment.

\section{References}

1. http://www.sina.com.cn.

2. Zhang MK, Liu ZY, Wang H (2010) Use of single extraction methods to predict bioavailability of heavy metals in polluted soils to rice. Commun Soil Sci Plan Anal 41: 820-831.

3. Suruchi, Khanna P (2011) Assessment of heavy metal contamination in differen vegetables grown in and around urban areas. Res J Environ Toxicol 5: 162-179.

4. Dumitrescu DV, Gurzău ES, Gurzău AE, Marchean D, Chera I, et al. (2012) Copşa Mică: Area and heavy metals pollution. Proc of PRE9: Protection and restoration of the environment IX, Greece.

5. Edward M, Muntean N, Duda M (2013) Heavy metal contamination of soil in Copşa Mică Area. ProEnvironment 6: 469-473.

6. Senila M, Tanaselia C, Rimba E (2013) Investigations on arsenic mobility changes in rizosphere of two ferns species using DGT technique. Carpathian J Earth Environ Sci 8: 145-154

7. Alia N, Sardar K, Said M, Salma K, Sadia A, et al. (2015) Toxicity and bioaccumulation of heavy metals in spinach (Spinacia oleracea) grown in a controlled environment. Int J Environ Res Public Health 12: 7400-7416.

8. Hassaan MA (2010) Study on concentration of some heavy metal in the lowe reach of Qalaa and Umum Drains to control metal pollution in Lake Mariut. MSc. Thesis. Alexandria University.

9. El-Rayis OA, Hassaan MA, Hemada EI (2014) Suitability of Lake Mariut drainage system (Qalaa and Umum Drains Waters) for water reuse. Blue Biotech J 3: 265-277.

10. USEPA (2011) Exposure Factors Handbook: 2011 Edition (Final report). Office of Research and Development, USA.

11. Bhuiyan MAH, Islam MA, Dampare SB, Parvez L, Suzuki S (2010) Heavy metal pollution of coal mine-affected agricultural soils in the northern part of Bangladesh. J Hazard Mater 173: 384-392.

12. Yan N, Liu W, Xie H, Gao L, Han Y, et al. (2015) Distribution and assessment of heavy metals in the surface sediment of Yellow River, China. J Environ Sci 39:45-51.

13. Zhang Z, Abuduwaili J, Jiang F (2015) Heavy metal contamination, sources and pollution assessment of surface water in the Tianshan Mountains of China. Environ Monit Assess 187: 33.

14. Zhu X, Ji H, Chen Y, Qiao M, Tang L (2012) Assessment and sources of heavy metals in surface sediments of Miyun Reservoir, Beijing. Environ Monit Assess 185: 6049-6062

15. Salati S, Moore F (2010) Assessment of heavy metal concentration in the Khoshk River water and sediment, Shiraz, Southwest Iran. Environ Monit Assess 164: 677-689.

16. Chandrasekaran A, Mukesh MV, Chidambaram S, Singarasubramania SR Rajendran S, et al. (2015) Assessment of heavy metal distribution pattern in the sediments of Tamirabarani River and estuary, east coast of Tamil Nadu, India. Environ Earth Sci 73: 2441-2452.

17. Ma X, Hang Z, Tian M, et al. (2016) Assessment of heavy metals contamination in sediments from three adjacent regions of the Yellow River using metal chemical fractions and multivariate analysis techniques. Chemosphere 144 264-272.

18. Jahanshahi R, Zare M (2015) Assessment of heavy metals pollution in groundwater of Golgohar iron ore mine area, Iran. Environ Earth Sci 74: 505520 .

19. Islam MS, Ahmed MK, Raknuzzaman M, Al-Mamun MH, Islam MK (2015) Heavy metal pollution in surface water and sediment: A preliminary assessment of an urban river in a developing country. Ecol Indic 48: 282-291.

20. Xie Z, Sun Z, Zhang H, Zhai J (2014) Contamination assessment of arsenic and heavy metals in a typical abandoned estuary wetland-a case study of the Yellow River Delta Natural Reserve. Environ Monit Assess 186: 7211-7232.

21. Bello S, Muhammad BG, Bature B (2017) Total excess lifetime cancer risk estimation from enhanced heavy metals concentrations resulting from tailings in Katsina steel rolling mill, Nigeria. J Material Sci Eng 6: 338. 
Citation: Bello S, Muhammad BG, Simon J, Bature B (2017) Development and Validation of a New Comprehensive Method for Heavy Metal Pollution Assessment in Soil Media. Int J Swarm Intel Evol Comput 6: 160. doi: 10.4172/2090-4908.1000160

22. Bello S, Zakari YI, Ibeanu IGE, Muhammad BG (2015) Evaluation of heavy metal pollution in soils of Dana steel limited dumpsite, Katsina state Nigeria using pollution load and degree of contamination indices. Am J Eng Res 4: 161-169

23. Bello S, Zakari YI, Ibeanu IGE, Muhammad BG (2016) Characterization and assessment of heavy metal pollution levels in soils of Dana steel limited dumpsite, Katsina state Nigeria using geo-accumulation, ecological risk and hazard indices. Am J Eng Res 5: 49-61.

24. Kumar PSH, Nasir UP, Rahma MPM (2009) Distribution of heavy metals in the core sediments of a tropical wetland system. Int J Environ Sci Technol 6: 225-232.
25. Tomlinson DL, Wilson JG, Harris CR, Jeffrey DW (1980) Problems in the assessment of heavy metal levels in estuaries and the formation of pollution index. Helgol Wiss Meeresonters 33: 566-572.

26. Yang YB, Sun LB (2009) Status and control countermeasures of heavy metal pollution in urban soil. Environ Protect Sci 35: 79-81.

27. Hakanson I (1980) An ecological risk index for aquatic pollution control, a sedimentological approach. Water Res 14: 975-1001.

28. Norman MT (1981) Environment and Health. Ann Arbor Inc. Michigan. pp. 367-406.

29. World Health Organization (WHO) (1996a) Trace elements in human nutrition and health. WHO, Geneva. 